\title{
Does a perception of increased blood safety mean increased blood transfusion? An assessment of the risk compensation theory in
} Canada

\author{
Mo Amin*1,2,4, Kumanan Wilson ${ }^{3}$, Alan Tinmouth ${ }^{4}$ and Paul Hébert ${ }^{4}$
}

Address: ${ }^{1}$ Department of Economics, University of Ottawa, 2 Saddle Crescent, Ottawa, ON, K1G 5L4, Canada, ${ }^{2}$ Canadian Coordinating Office for Health Technology Assessment, 600-865 Carling Avenue, Ottawa, ON, K1G 5L4, Canada, ${ }^{3}$ Department of Medicine, University of Toronto, 190 Elizabeth Street, Suite 3-805, Toronto, ON, M5G 2C4, Canada and ${ }^{4}$ Clinical Epidemiology Programme, Ottawa Health Research Institute, 501 Smyth Road, Box 201, Ottawa, ON, K1H 8L6, Canada

Email: Mo Amin* - mo.amin@sympatico.ca; Kumanan Wilson - kumanan.wilson@uhn.on.ca; Alan Tinmouth - atinmouth@ohri.ca; Paul Hébert - phebert@ottawahospital.on.ca

* Corresponding author

Published: 07 June 2004

BMC Public Health 2004, 4:20
Received: II February 2004

Accepted: 07 June 2004

This article is available from: http://www.biomedcentral.com/147I-2458/4/20

(C) 2004 Amin et al; licensee BioMed Central Ltd. This is an Open Access article: verbatim copying and redistribution of this article are permitted in all media for any purpose, provided this notice is preserved along with the article's original URL.

\begin{abstract}
Background: The risk compensation theory is a widely used concept in transport economics to analyze driver risk behaviour. This article explores the feasibility of applying the theory in blood transfusion to raise important questions regarding the increased blood safety measures and their possible effects on blood usage (e.g., the appropriateness in transfusion). Further, it presents the findings of a pilot survey of physicians in Canada.

Discussion: While studies have attempted to define transfusion appropriateness, this article argues that if the risk compensation theory holds true for transfusion practice, physicians may actually be transfusing more. This may increase the possibility of contracting other unknown risks, such as the variant Creutzfeldt-Jakob Disease (VCJD), as well as increasing the risk of non-infectious transfusion risks, such as transfusion reactions.

Summary: A much larger study involving psychosocial assessment of physician decision making process to fully assess physician behaviour within the context of risk compensation theory and transfusion practice in Canada is needed to further explore this area.
\end{abstract}

\section{Background}

The risk compensation theory postulates that, in performing any action, people accept a certain level of 'subjectively' estimated risk of the outcome associated with the action, and compensate the level of risk with an expected level of benefit they hope to gain from that action [1]. In other words, people try to equate the probability of a risky outcome with that of a beneficial outcome [1]. In reality, people seldom rate their risk subjectively before committing any action, and then compare that risk value with the posterior or experienced risk value while performing the action. Instead, they continually perform risk rating by updating the risk information, and compare this posterior risk value with the amount of risk they were originally willing to accept (i.e., the prior risk value) $[1,2]$. Typically, if the posterior risk is lower than the prior risk people tend to engage in actions that de facto increase their risk exposure; and if the posterior risk value is higher than the prior risk value people tend to exercise caution and reduce their risk exposure. 
The theory has been widely applied in transport economics to assess safety improvement measures in passenger vehicles, and to perform outcome analysis concerning driver risk behaviour. Studies suggest that increased safety measures in vehicles lead to increased driver exposure to risks, which in turn, leads to increased fatal outcomes [14]. These studies suggest that people consume roughly all the enhanced safety imposed upon them in other desirable yet risky activities, such as more exciting driving, to fight boredom.

Further, the theory has also been applied in health economics to manage health insurance related risk pooling and in the area of occupational health [5-8].

\section{How about risk compensation in blood transfusion?}

The blood system in Canada has undergone various changes to make the blood system safer than ever before. Safety measures based on precautionary principles have been put in place and surveillance of the blood system has improved significantly. The blood operators, in their mission statements, clearly state that their utmost task is to ensure the safety of blood. Consequently, they have introduced several quality assurance procedures (e.g., Nucleic Acid Amplification Technology (NAT) testing for HIV and Hepatitis-C, Human T-Lymphotropic Virus (HTLV) test, universal leukoreduction of blood, rejection of blood unit indicating initial 'false positive' result, etc.) to bolster public confidence in the blood system. In addition, the blood operators have introduced a donor deferral policy since October 1999 to protect the blood supply from theoretical contamination from variant Creutzfeldt-Jakob disease (vCJD). Finally, the blood operators in Canada have introduced a NAT-based test to detect West Nile Virus (WNV) since July 2003 [9].

The risk compensation theory, if applied, implies that these safety measures may provide positive signals to physicians across Canada, and may enable physicians to form a prior belief about the safety of blood. This prior belief may actually lead physicians to adopt a liberal transfusion regime until they face a new risk value when they may alter their behaviour. In other words, physicians may tend to transfuse more due to increased blood safety measures since physicians' posterior risks associated with blood transmissible diseases gradually diminish. This belief is further reinforced with decreasing risk of HIV and Hepatitis-C associated with transfusion $[10,11]$. All these reasons may give rise to increased transfusion, which may increase the risk of contracting other unknown infectious risks. Increased transfusion could also lead to harm due to noninfectious risks, such as transfusion reactions [12].
One way to empirically test the applicability of the theory is to analyze blood utilization figures before and after the blood system reorganization. However, since there is no data available on blood utilization in Canada at present, we used the data on blood collection as a proxy since the demand for and supply of blood are (or at least have been) closely matched [13]. Collection figures suggest that the number of blood units collected during the late 1980s was over 1.2 million a year and the number dropped to less than 700,000 a year by 1995 , and has since increased. It stood at around 1 million (CBS and Héma-Québec combined) by the end of 2000 [13]. Considering that there was likely to have been no significant difference in the patient population over this time that would have required greater usage of blood and blood products, we may hypothesize that the introduction of safety measures might have assured the physician community that blood was safer and therefore increased the use of blood. However, this approach of looking at the issue is very broad and does not take into account the individual physician's decision making process and many other possible confounders such as exogenous demand and supply side shocks, blood system policy shifts, loss of donor confidence and the introduction of blood safety and donor deferral policies. An example of the effect of such factors was demonstrated by Brecher and Goodnough, who indicated that improved haemovigilance in the US may have reduced the use of pre-donated autologous blood [14].

Another area of interest where there has been an exponential increase in use is the human plasma derived intravenous immunoglobulin (IVIG), a commercial blood product where users may be subject to commercial marketing techniques. The use of IVIG, which is indicated for over 100 indications, has increased manifold during the past few years [15]. Although there exist clear clinical benefits in using the IVIG for some indications, there remain many 'grey' areas where the use has not been proven to be clinically beneficial [16]. Notwithstanding these, the use of IVIG has been growing unabated and the cost associated with it is fast increasing. Alike blood, IVIG may also be subject to risk compensation theory for its increased utilisation.

\section{Pilot survey of blood and blood products users}

In order to better understand physician behaviour surrounding the safety of blood and blood products, and to test the validity of the hypothesis that "improved blood safety increases the use of blood by physicians", we conducted a telephone interview of 45 physicians across Canada. Respondents were selected randomly from the list of names and contact details for internists, cardiovascular surgeons and haematologists available from the Canadian Medical Association Directory 2002. There were 27 
respondents from Ontario, 10 from Alberta, four from Nova Scotia, two each from British Columbia and Québec. Of the 45 physicians responded, 28 were internists, 10 were cardiovascular surgeons, and seven were haematologists.

The survey asked the following five questions each of which had three possible choices: "yes", "no" and "unsure":

Question 1: Do you think the safety of blood and blood products in Canada has increased and improved since the Krever Commission Report?

Question 2: Do you have confidence over the Canadian blood system in terms of its safety?

Question 3: Do you think the increased and improved safety of blood and blood products may influence you to increase blood utilisation (in clinically appropriate situations)?

Question 4: Have you increased the usage of blood and blood products during the past five years?

Question 5: Will you be concerned about and hence decrease your level of blood and blood products utilization if there is any new viral and/or bacterial threat to blood?

The findings indicate that the majority $(\mathrm{N}=43, \sim 96 \%)$ of respondents think that the safety of blood and blood products in Canada has increased and improved since the Krever Commission report in 1997. Around 93\% ( $\mathrm{N}=42)$ of the respondents indicated that they have confidence over the safety of the Canadian blood system. Thirty respondents $(\sim 67 \%)$ indicated that their prescribing pattern might be influenced by increased and improved safety of blood and blood products, while 13 ( 29\%) replied negatively and two were not sure ( $4 \%)$. About $80 \%(\mathrm{~N}=36)$ of respondents suggested that their usage of blood and blood products increased over the past five years, and around 93\% ( $\mathrm{N}=42)$ of respondents opined that they would be concerned about and therefore reduce the level of blood and blood products utilization following a new viral and/or bacterial threat in the future.

\section{Discussion}

We have explored the possibility of applying the risk compensation theory in blood transfusion practice. If applied, the risk compensation theory suggests that safety measures may possibly increase the utilization of blood and lead to unnecessary transfusion that may defeat the overall aim for achieving appropriateness in transfusion. There were several limitations of our analysis: a) we had a very limited sample of physicians in our survey; b) we did not consider the public's perception of safety of blood; and c) risks of serious hazards of transfusion were not considered. Further we could not ascertain the degree to which physicians might be influenced by such increased safety measures. This requires a much larger study involving psychosocial assessment of physician decision making to fully assess physician behaviour within the context of risk compensation theory and transfusion practice in Canada. Notwithstanding these limitations, we have shown that physicians might be influenced in their utilisation by the increased and improved safety of blood and blood products. Blood systems should consider monitoring for such an effect when introducing new safety measures. Furthermore, they should bear in mind the importance of preventing unnecessary transfusion to reduce non-infectious risks and unknown infectious risks.

\section{Summary}

This pilot study has indicated that the framework used to analyze risk behaviour within the risk compensation theory could be extended and applied in the blood transfusion discipline to assess physician behaviour in Canada.

\section{Authors' contributions}

MA, KW and PH conceived of and designed the study and drafted the manuscript. Data were collected and analyzed by MA and MA, AT, KW and PH took part in critical revision of the manuscript for important intellectual content.

\section{Competing interests}

None declared.

\section{Acknowledgements}

Kumanan Wilson is a recipient of the Canadian Institutes for Health Research (CIHR) New Investigator Award, and Paul C. Hébert is an Ontario Ministry of Health and Long Term Care Career Scientist.

\section{References}

I. Wilde G]: The theory of risk homeostatis: implications for safety and health. Risk Analysis 1992, 2:209-258.

2. Wilde GJ: Risk homeostatis theory and its promise for improved safety. In Challenges to accident prevention: the issue of risk compensation processes Edited by: Trimpop RM, Wilde GJ. Groningen: Styx Publications; 1994.

3. Fuller R: The task performance interface model of the driving process. Manuscript Trinity College, Dublin; 1999.

4. Evans L: Risk homeostatis theory and traffic accident data. Risk Analysis 1986, 6:8I-94.

5. Philips DR: Ageing in the Asian Pacific region: issues, policies and future trends. London: Routeledge; 2000.

6. Adams J, Hillman M: The risk compensation theory and bicycle helmets. Injury Prevention 200I, 7(2):86-88.

7. Chapman S, Haddad S, Sindhusake D: Do work place smoking bans cause smokers to smoke "harder"? Results from a naturalistic observational study. Addiction 1997, 92:607-610.

8. Moeller DW: Environmental Health Cambridge: Harvard University Press; 1992.

9. West Nile Virus Update [http://www.bloodservices.ca/cen treapps/internet/uw v502 mainengine.nsf/0/ 87E5FI6FC7398A4385256C53004D32DC?OpenDocument] 
10. Busch MP, Kleinman SH, Nemo G]: Current and emerging infectious risk of blood transfusions. JAMA 2003, 289(8):959-962.

11. Hollinger FB, Kleinman S: Transfusion transmission of West Nile Virus: a merging of historical and contemporary perspectives. Transfusion 2003, 43(8):992-997.

12. Kleinman S, Chan P, Robillard P: Risks associated with transfusion of cellular blood components in Canada. Transfusion Medicine Reviews 2003, I7(2): 120-162.

13. Héma-Québec Annual Report 2000/0I [http://www.hema-que bec.qc.ca/E/presse/publications.htm]

14. Brecher ME, Goodnough LT: The rise and fall of preoperative autologous blood donation (editorial). Transfusion 2002, 42(12):1618-22.

15. CBS: Prescribing IVIG: Prioritizing Use and Optimizing Practice. In Proceedings of the IVIG Consensus Conference: Toronto, Canada . 3-4 October 2000

16. BCPBCO: IVIG Utilization Management Handbook First edition. Vancouver: British Columbia Provincial Blood Coordinating Office; 2002.

\section{Pre-publication history}

The pre-publication history for this paper can be accessed here:

http://www.biomedcentral.com/1471-2458/4/20/prepub

Publish with Biomed Central and every scientist can read your work free of charge

"BioMed Central will be the most significant development for disseminating the results of biomedical research in our lifetime. "

Sir Paul Nurse, Cancer Research UK

Your research papers will be:

- available free of charge to the entire biomedical community

- peer reviewed and published immediately upon acceptance

- cited in PubMed and archived on PubMed Central

- yours - you keep the copyright

Submit your manuscript here:

http://www.biomedcentral.com/info/publishing_adv.asp 